Jiang, Y., Allocca, C., and Chen, Q. 2004. "Validation of CFD simulations for natural ventilation”, International Journal of Ventilation, 2(4), 359-370.

\title{
Validation of CFD Simulations for Natural Ventilation
}

\author{
Yi Jiang ${ }^{1}$, Camille Allocca ${ }^{1}$, and Qingyan Chen $^{2}$ \\ ${ }^{1}$ Department of Architecture, Massachusetts Institute of Technology, Cambridge, MA 02139, USA \\ ${ }^{2}$ School of Mechanical Engineering, Purdue University, West Lafayette, IN 47907, USA
}

\begin{abstract}
Natural ventilation, which may provide occupants with good indoor air quality and a high level of thermal comfort, and reduce energy costs, has become an important sustainable strategy in building designs. This investigation used three computational fluid dynamics (CFD) models: steady Reynolds averaged NavierStokes equation (RANS) modeling, unsteady RANS modeling, and large eddy simulation (LES) to study both wind-driven and buoyancy-drive natural ventilation. The validation of the CFD models used the experimental data of wind-driven natural ventilation obtained from a wind tunnel with a scaled building model and the data of buoyancy-driven ventilation obtained from a full-scale chamber. LES results seem more accurate and informative than those obtained with the RANS modeling, but with severe penalty in computing time. This investigation has also analyzed turbulence energy spectra of natural ventilation. The peak turbulence energy for wind-driven natural ventilation is at frequencies higher than that for buoyancy driven natural ventilation. Thus, the fluctuating flow field plays a more important role in determining ventilation rate for wind-driven natural ventilation than for buoyancy-driven natural ventilation.
\end{abstract}

Keywords: computational fluid dynamics (CFD), large eddy simulation (LES), Reynolds averaged Navier-Stokes equation (RANS) modeling, experimental measurements, natural ventilation

\section{Introduction}

Natural ventilation, which may provide occupants with good indoor air quality and a high level of thermal comfort, and reduce energy costs, has become an important sustainable strategy in building designs, and is thus attracting considerable interests from designers (Etheridge and Sandberg 1996, and Allard 1998).

In a naturally ventilated building, air is driven in and out due to pressure differences produced by wind and/or buoyancy forces. Three approaches are available to study natural ventilation: empirical models, experimental measurements, and computational fluid dynamics (CFD) simulations. The empirical models, as reviewed by Allocca (2001), are often developed from analytical solutions and experimental data. Although the models are very useful for natural ventilation design, they could not provide sufficient information on natural ventilation and may not be accurate. The experimental measurements have been an effective tool to obtain realistic information about natural ventilation (Katayama et al. 1992). The measurements are very expensive and time consuming. In addition, the data may not be in great enough detail for understanding the mechanism of natural ventilation.

On the other hand, CFD is becoming popular due to its informative results, low labor costs, and little equipment requirement. CFD can be divided into Reynolds averaged Navier-Stokes equation (RANS) modeling and large eddy simulation (LES). RANS is a popular CFD method that uses turbulence models to simulate turbulent flow. Since natural ventilation is a very typical unsteady flow problem, the study of natural ventilation by RANS may need a transient simulation. LES calculates large-scale flow motion while simulating small-scale flow motion by subgrid-scale models in transient form. The computing costs for the steady RANS simulation, unsteady RANS simulation, and LES are different. Which CFD method is most suitable for natural ventilation studies in terms of accuracy, informative results, and computing time? This paper will try to answer the question by using the three CFD methods for simulating wind- and buoyancy-driven natural ventilation and will compare the computed results with experimental data. 


\section{CFD Method}

This section will briefly introduce the three CFD methods. Steady and unsteady RANS modeling solves the Reynolds averaged Navier-Stoke equations:

$$
\frac{\partial \rho U_{i}}{\partial t}+\frac{\partial \rho U_{i} U_{j}}{\partial x_{j}}=-\frac{\partial P}{\partial x_{i}}+\frac{\partial}{\partial x_{j}}\left(\mu \frac{\partial U_{i}}{\partial x_{j}}-\rho \overline{u_{i} u_{j}}\right)
$$

where

$\mathrm{t}=$ time

$\rho \quad=\quad$ air density

$\mathrm{U}_{\mathrm{i}}, \mathrm{U}_{\mathrm{j}}=$ mean air velocity in $\mathrm{x}_{\mathrm{i}}$ and $\mathrm{x}_{\mathrm{j}}$ direction, respectively

$\mathrm{x}_{\mathrm{i}}, \mathrm{x}_{\mathrm{j}}=$ coordinate

$\mathrm{P} \quad=\quad$ mean air pressure

$\mu \quad=\quad$ air viscosity

$\rho \overline{u_{i} u_{j}}=\quad$ Reynolds stresses

- $\quad=\quad$ averaging

A turbulence model is needed to model the unknown Reynolds stresses through turbulent eddy viscosity, $\mu_{\mathrm{t}}$. This investigation uses the standard $\mathrm{k}-\varepsilon$ turbulence model (Launder and Spalding 1974):

$\mu_{\mathrm{t}}=\mathrm{C}_{\mu} \rho \mathrm{k}^{2} / \varepsilon$

where $\mathrm{C}_{\mu}$ is a constant, $\rho$ is air density, and $\mathrm{k}$ and $\varepsilon$ are two additional independent variables, which need to be solved in a similar way as the velocities.

For steady RANS, the first term on the left side of the equation is set to be zero. On the other hand, LES model filters the Navier-Stokes equation to obtain

$$
\frac{\partial \rho \overline{u_{i}}}{\partial t}+\frac{\partial}{\partial x_{j}}\left(\overline{\rho u_{i} \bar{u}_{j}}\right)=-\frac{\partial \bar{p}}{\partial x_{i}}+\frac{\partial}{\partial x_{j}}\left(\mu \frac{\partial \bar{u}_{i}}{\partial x_{j}}-\rho\left(\overline{u_{i} u_{j}}-\bar{u}_{i} \bar{u}_{j}\right)\right)
$$

where

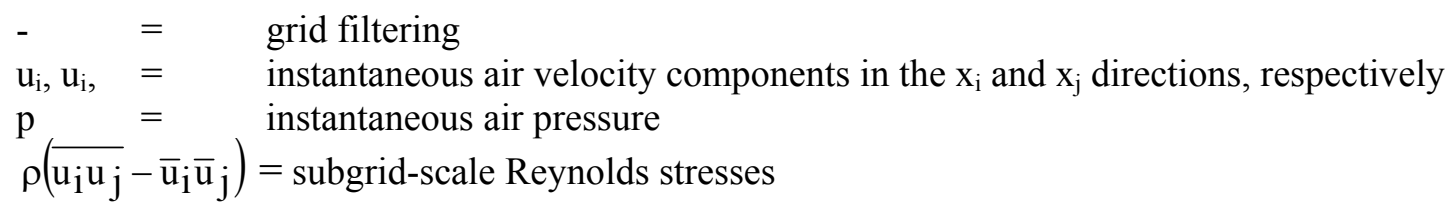

The subgrid-scale Reynolds stresses in Equation (3) are unknown and must be modeled with a subgridscale model. In this investigation, both the Smagorinsky subgrid-scale (SS) model (Smagorinsky, 1963) and the filtered dynamic subgrid-scale (FDS) model (Zhang and Chen 2000) were used. 


\section{Validation of the CFD Results}

This section will describe how the three CFD methods were used to simulate wind-driven and buoyancydriven natural ventilation. The computed distributions of the air temperature, velocity, and turbulence properties, such as energy spectra, will be validated by corresponding experimental data.

\subsection{Wind-Driven Natural Ventilation}

The wind-driven natural ventilation study uses the case designed by Jiang et al (2003). This case employed a wind tunnel with a scaled building model to obtain flow data for wind-driven natural ventilation in a building. The experiment measured airflow around and within a simple, cubic, buildinglike model in a boundary-layer wind tunnel. Two-dimensional mean and fluctuating velocity components were captured using a laser Doppler anemometer. Measurements were done in front, inside, and behind the building model. The pressure distributions along the building model surface were also measured. Three different natural ventilation cases were studied: single-sided ventilation with an opening in the windward wall, single-sided ventilation with an opening in the leeward wall, and cross ventilation with openings in both windward and leeward walls. The Reynolds number studied is $1.4 \times 10^{5}$ based on the velocity at the building height in the wind-tunnel inlet.

Figure 1 shows the velocity distribution in the middle section for the single-sided ventilation with an opening in the windward wall. All three CFD models can properly predict the airflow field on the windward side, which shows a large reverse flow near the ground. In the leeward region, however, both steady and unsteady RANS models predict a larger recirculation zone than that in the experiment, while LES correctly predicts the airflow patterns in that region. The same results have been observed previously (Rodi et al 1997). The details of how these flow patterns differ around and inside this building model become quite clear when next comparing the velocity profiles along streamwise locations.
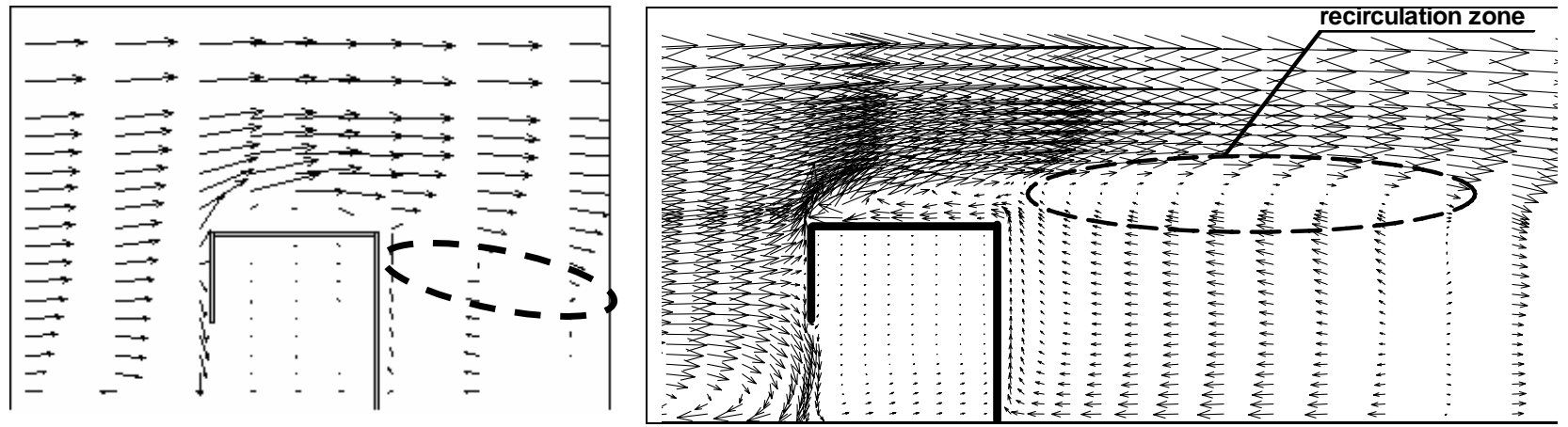

(a) Experimental measurements

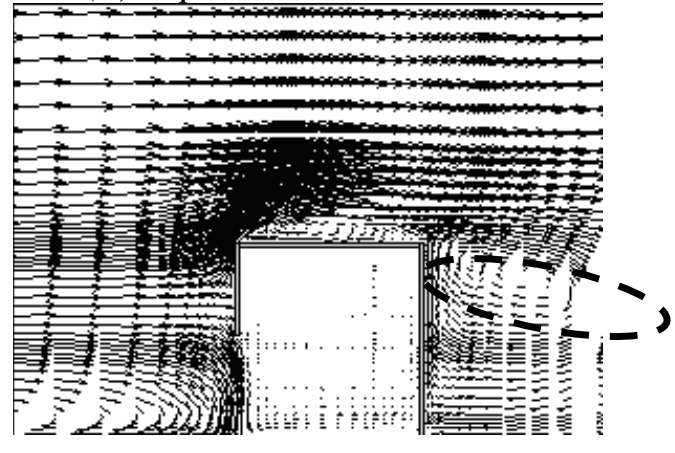

(c) LES results (b) Steady RANS results

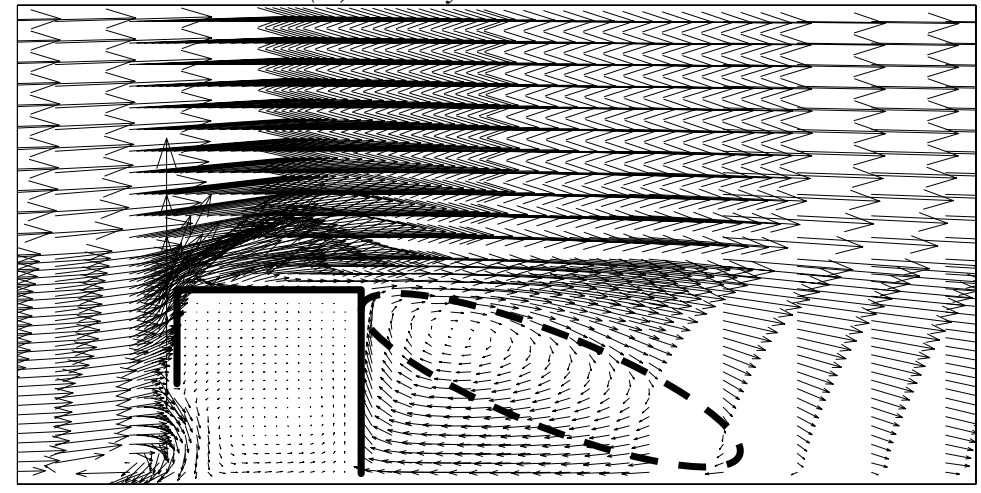

(d) Unsteady RANS results

Figure 1. Mean velocity vector fields at the center section 
Figure 2 shows the locations where the computed results from the three CFD methods are compared with the measured data, and Figure 3 shows the comparison. The agreement between the CFD predictions and the experimental results on the windward locations is very good. On the leeward side, however, both the steady and unsteady RANS models tend to over-predict the recirculation region. This problem has an impact on predicting single-sided ventilation with leeward openings and cross ventilation with openings on both sides of a building. The results from LES agree much better with the experimental data, and the discrepancies are less than $5 \%$ in most regions.

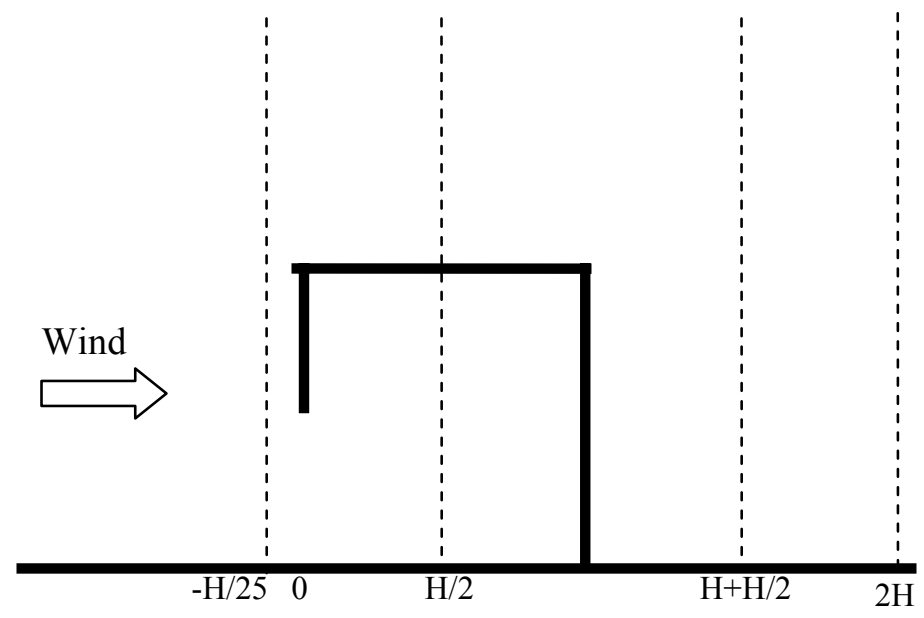

Figure 2. The locations where comparison of the CFD results with experimental data were made in the mid-section (The thick lines represent the building model and the ground).

Since the steady and unsteady RANS modeling could not correctly predict the airflow pattern, it is not meaningful to validate their ability to predict second-order turbulence quantities. In addition, the k$\varepsilon$ model calculates kinetic energy and dissipation rate, not the individual Reynolds stresses. On the other hand, LES could also predict Reynolds stresses with acceptable accuracy (Jiang et al. 2003), although the discrepancies between the computed results and measured data are larger than those for air velocity and temperature.

Table 1 summarizes the performance of the three CFD methods in terms of computing time, available airflow information, and accuracy. The results for ventilation rate are the conclusions obtained from Jiang and Chen (2001). In that study, we also reported that FDS subgrid model used in LES is better than the SS model. Although unsteady RANS model can slightly improve the results over steady RANS, the discrepancy is still significant between the measured data and computed results. Furthermore, the unsteady RANS model requires much more computing time than the steady RANS does. Therefore, the unsteady RANS model is not suggested for natural ventilation studies and will be not used for the buoyancy-driven ventilation study reported in the next section. 

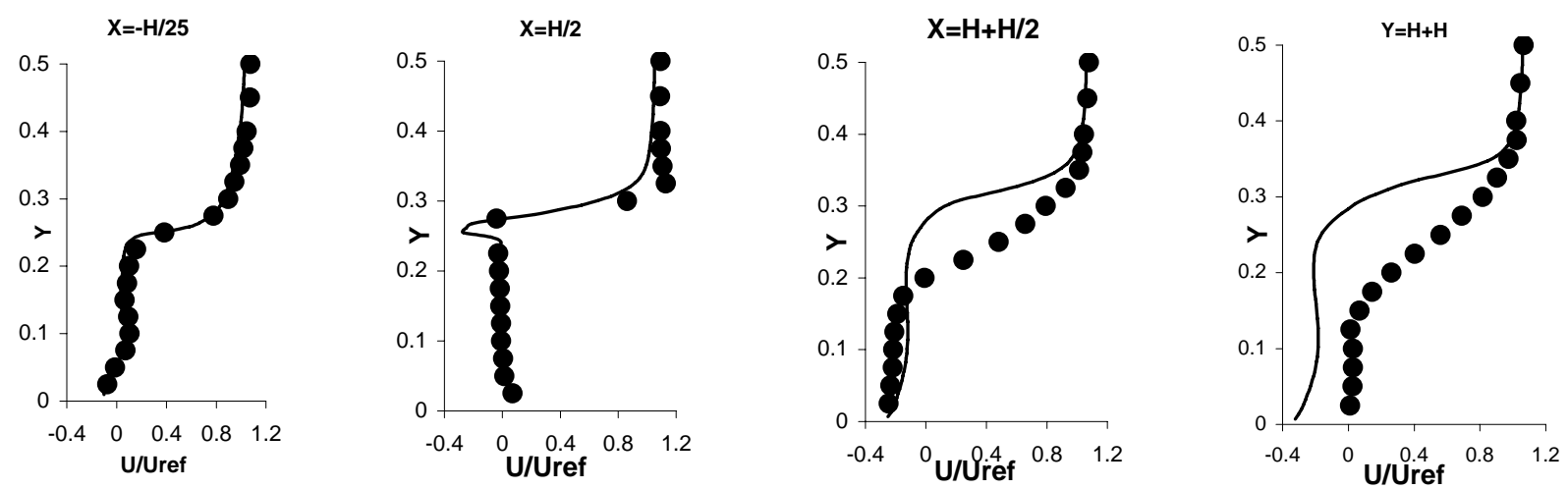

(a) Steady RANS modeling results (Dots: experimental data; Solid line: RANS modeling)
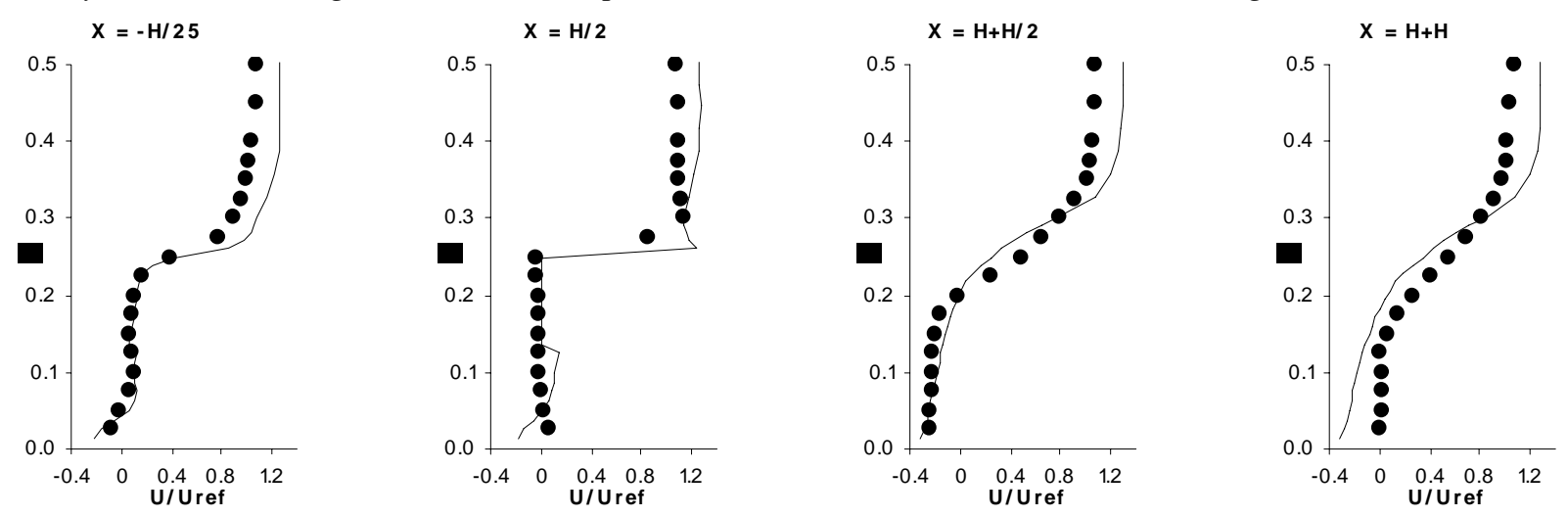

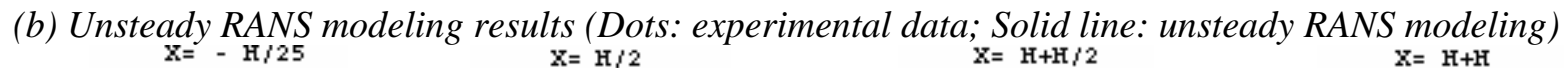
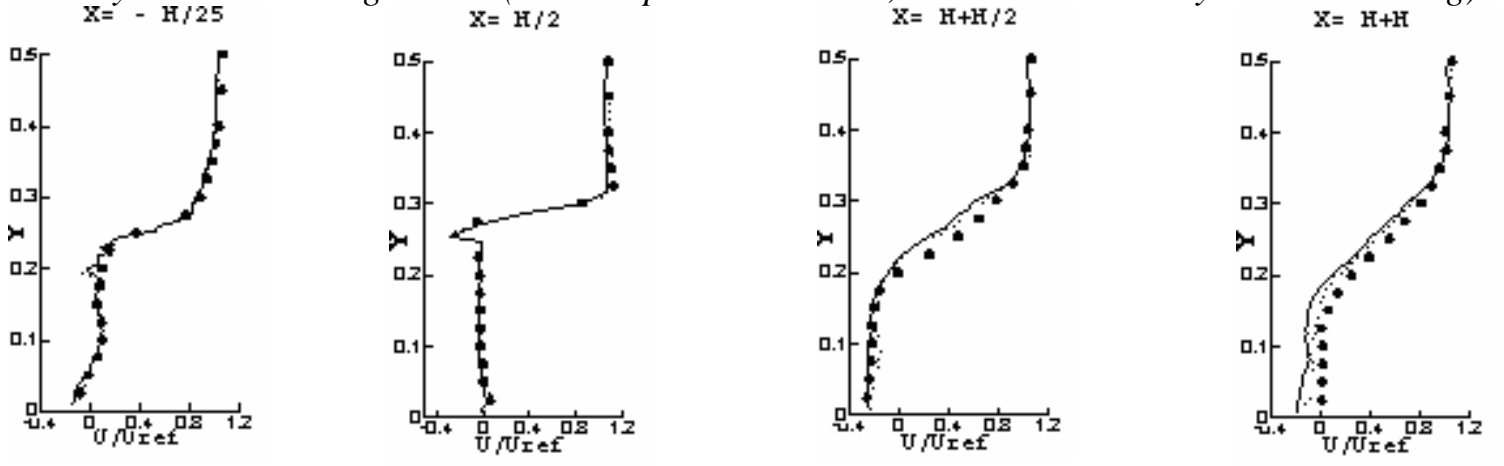

(c) LES results (Dots: experimental data; Solid line: SS model; Dotted line: FDS model)

Figure 3. Comparison of CFD results of air velocity profile in different horizontal sections for singlesided, windward ventilation. (Uref is the reference velocity at the building height and $2 \mathrm{H}$ in front of the building.).

Table 1. Comparison of three CFD models for the study of single-sided, windward ventilation case.

\begin{tabular}{|l|l|l|l|}
\hline & CPU & Flow field distribution & Ventilation rate \\
\hline Steady RANS & $2 \mathrm{~h}$ & No detailed turbulence information and not very accurate & Not accurate \\
\hline Unsteady RANS & $40 \mathrm{~h}$ & No detailed turbulence information and not very accurate & Not accurate \\
\hline LES & $140 \mathrm{~h}$ & Detailed turbulence information and accurate & Accurate \\
\hline
\end{tabular}


Hanzawa, et al. (1987) pointed out that the study of energy spectra could help to reveal the impact of turbulence on thermal comfort, which is an important factor in evaluating natural ventilation performance. Therefore, it is necessary to validate the CFD models for their ability to predict the energy spectra. Figures 4 and 5 illustrate the measured energy spectral distributions along the building model for singlesided, leeward ventilation and cross ventilation, respectively. For the wind-driven, single-sided natural ventilation, the energy spectral ranges widely from $0.1 \mathrm{~Hz}$ to $100 \mathrm{~Hz}$ with its peak energy at about $1 \mathrm{~Hz}$. Ohba et al. (2001) did experiments in a wind-tunnel for cross ventilation, and obtained similar results. This suggests that the flow contains both low-frequency large eddies and high-frequency small eddies.

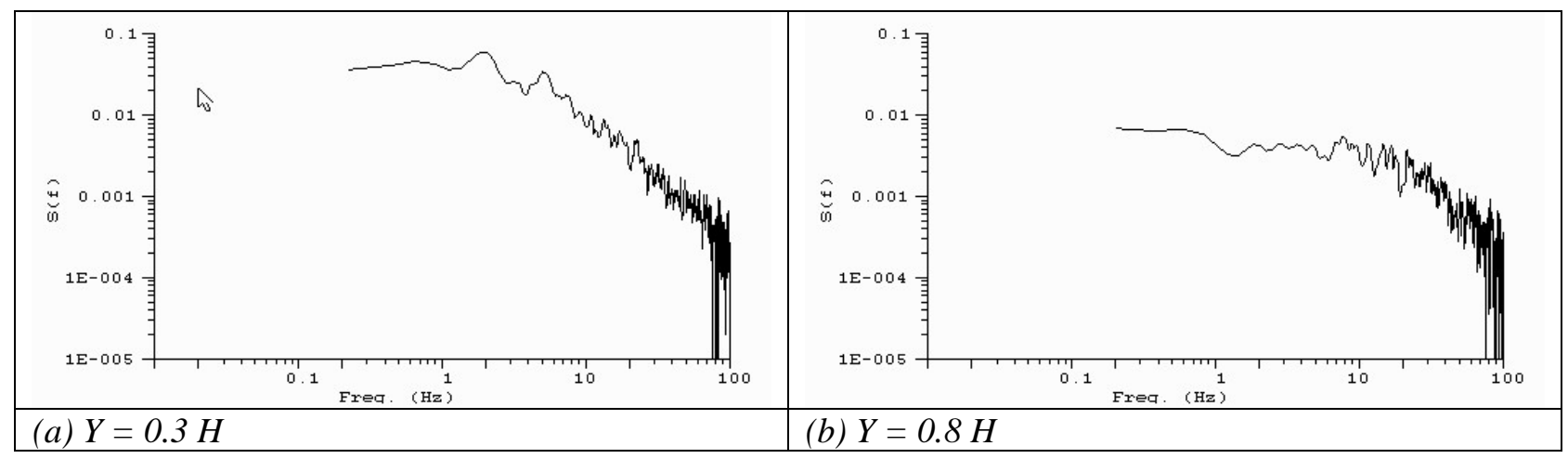

Figure 4. The measured energy spectra of the velocity component, $u$, at two different heights outside of the building model in the single-side, leeward ventilation case at $\mathrm{X}=\mathrm{H}+\mathrm{H} / 25$ (Outside of the model).

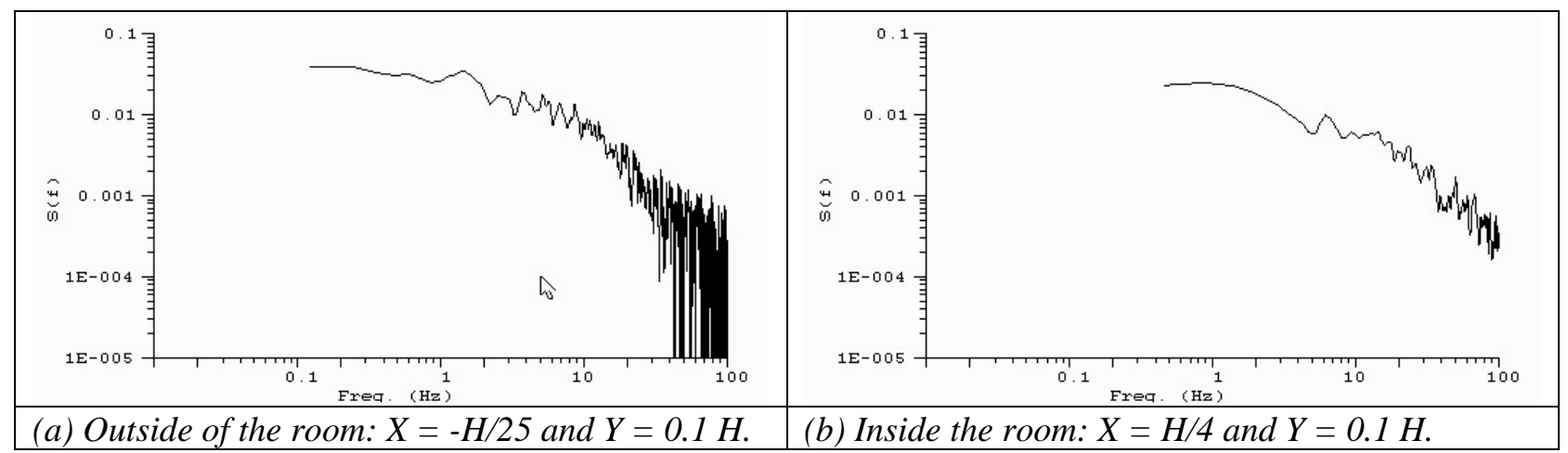

Figure 5. The measured energy spectra of the velocity component, $u$, in the vicinity of the opening in the cross-ventilation case.

Note that Figure 4 uses the data measured outside the building model but close to the opening. In the single-sided ventilation cases, the time series of the collected velocities inside the building models were not continuously distributed. Continuous collection of velocity data is crucial to conduct meaningful energy spectral analysis (Jiang 2002). Therefore, it is not practical to do energy analysis inside the building model. For the cross ventilation case, the velocity data can be continuously collected and energy spectra can be used to analyze both the inside and outside of the building model as shown in Figure 5.

The computed turbulence energy spectra with LES are shown in Figure 6 and Figure 7 for single-sided, leeward ventilation and cross ventilation, respectively. The shapes of the computed spectra distributions are very similar to those from the measurements, which qualitatively validate the LES results. The energy spectra distributions at the opening can be also computed with LES, although they were not available from the measurements. Figure 6(a) is taken at the lower part of the opening and shows that flow 
maintains its outdoor characteristics after passing through the opening, because the energy spectra look the same between indoors and outdoors. At the higher part of the opening as shown in Figure 6(b), the frequency of the peak turbulence energy in the outdoor airflow is around $1 \mathrm{~Hz}$ that is one magnitude order higher than that in the indoor airflow. The figure also shows that the indoor airflow does not contain as much energy as the outdoor airflow. The turbulence energy from the outdoor air is dissipated due to friction in flow boundary layers in the room. The airflow in outside of the upper part of the opening is mainly influenced by the wind, because the outgoing flow from the room to the outside is relatively small that has a small impact on outdoor airflow. Therefore, the flow characteristics between inside and outside in the upper part of the opening are different as shown in Figure 6(b).

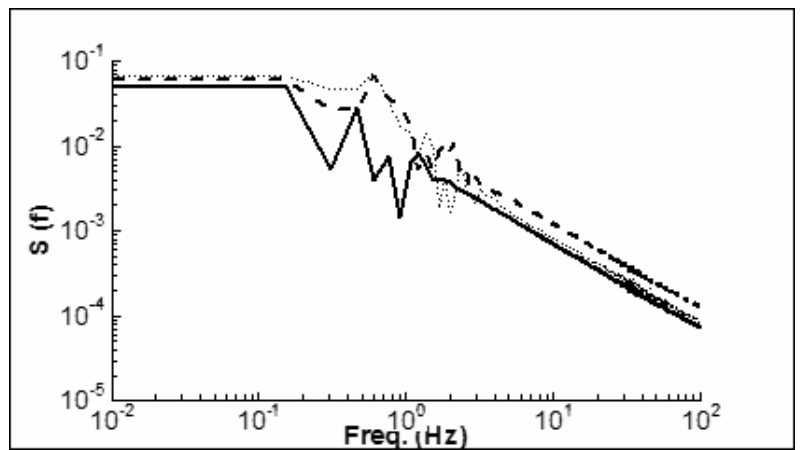

(a) $Y=0.3 H$

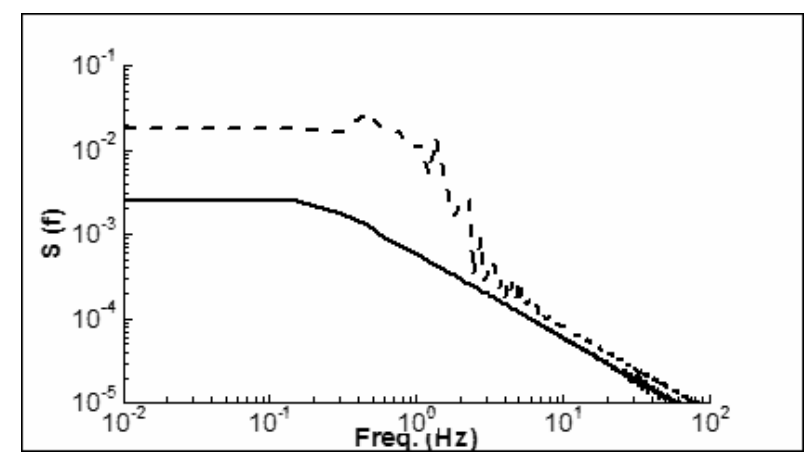

(b) $Y=0.8 H$

Figure 6. The computed turbulence energy spectra of u-component at two different heights in the opening vicinity for the single-sided, leeward ventilation case. Solid line: $X=3 / 4 \mathrm{H}$ (inside the model); Dotted line: $X=H$ (at the opening); Dashed line: $X=H+H / 25$ (outside of the model).

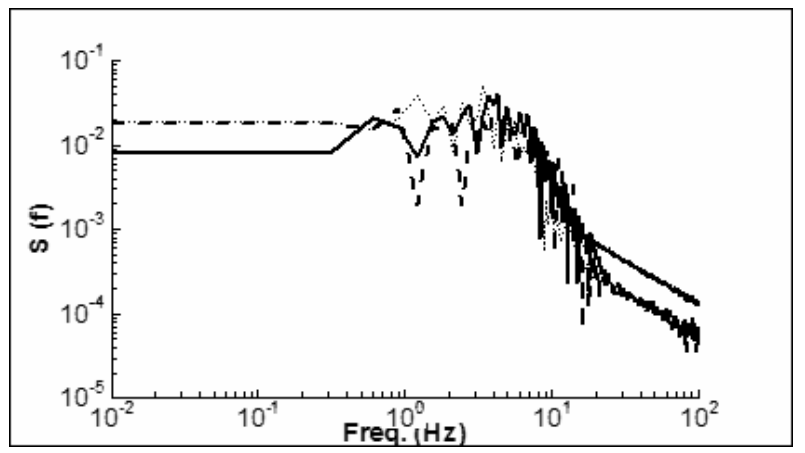

(a) $Y=0.3 H$

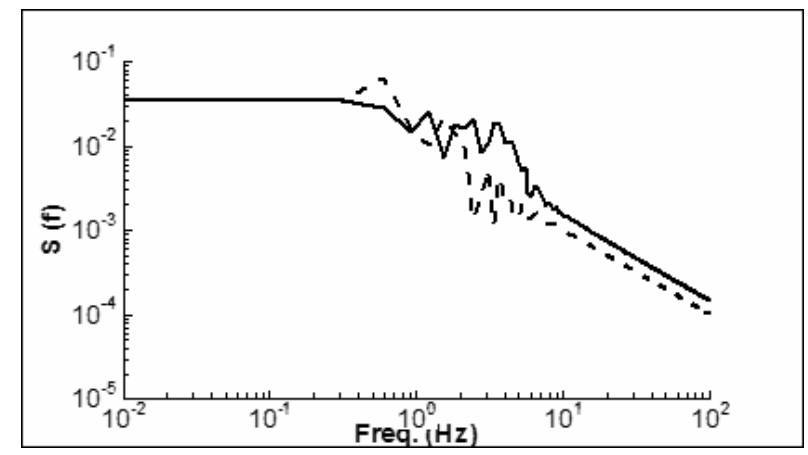

(b) $Y=0.8 H$

Figure 7. The computed turbulence energy spectra of $u$-component in the opening vicinity for the cross ventilation case. Solid line: $X=H / 4$ (inside the model); Dotted line: $X=0$ (at the opening); Dashed line: $X=-H / 25$ (outside of the model).

For cross ventilation (Figure 7), the turbulence energy spectra of the air velocity are almost the same outside and inside of the building model. This is because the outdoor airflow can enter the building easily and maintains its turbulence characteristics after passing through the openings.

\subsection{Buoyancy-Driven Natural Ventilation}

To validate the CFD models for buoyancy-driven natural ventilation, this investigation used the case from Jiang and Chen (2003) that used a full-scale environmental chamber. The environmental chamber was placed in a large laboratory space. The chamber was used to simulate an indoor environment and the laboratory space to simulate a windless outdoor environment. A baseboard heater was placed in the chamber to generate buoyancy forces. The chamber door was open to the laboratory space to simulate a 
single-sided ventilation driven by buoyancy forces. When the lower half of the door was blocked, the situation turns into a room with an open "window." The air velocity and temperature distributions were measured with hot-sphere anemometers at different heights in different locations inside and outside of the chamber. The experiment also used a tracer gas system to measure the ventilation rate of the room.

Figures 8 and 9 compare the computed temperature and velocity profiles with the experimental data for the door case. In general, the computed results agree reasonably with the experiment. The LES models give slightly better results than the steady RANS modeling. Figure shows that within the chamber, the air temperature increases with height. But the temperature profile is not linearly distributed, with the largest temperature stratification occurring at the middle height of the room $(0.9 \mathrm{~m} \sim 1.3 \mathrm{~m}$ from the floor). Figure 9 shows that the high-speed regions are near the ceiling and near the floor. In the middle height, the air speeds are very low. This explains why the temperature stratification in the middle section is very high, since the air mixing in this part is poor.

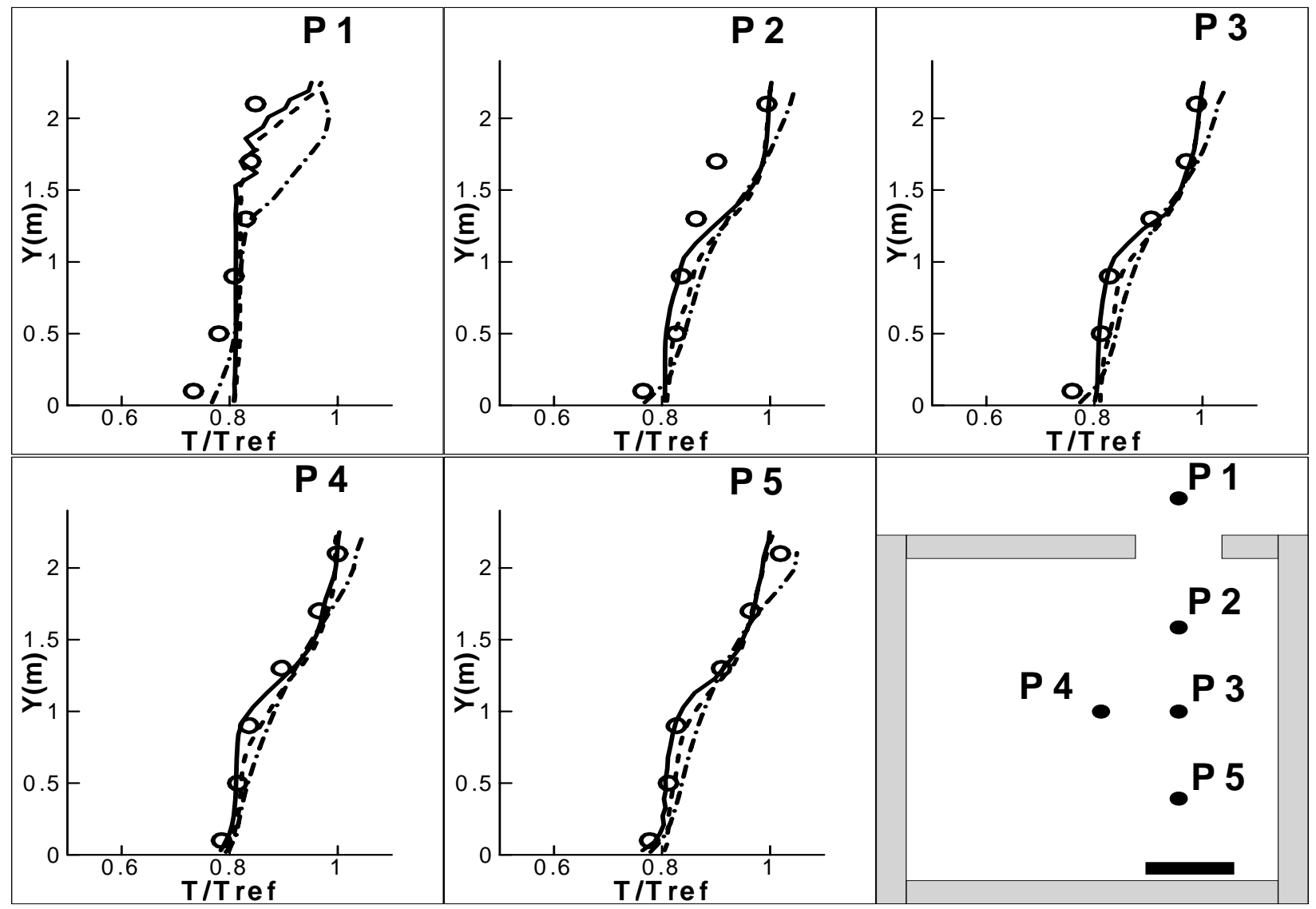

Figure 8. Comparison of the computed temperature profiles with the measured data at the five positions in and around the chamber with an open door. Circles: Experimental data; Solid lines: the SS model of LES; Dashed lines: the FDS model of LES; Dash-dot lines: the steady RANS modeling. 


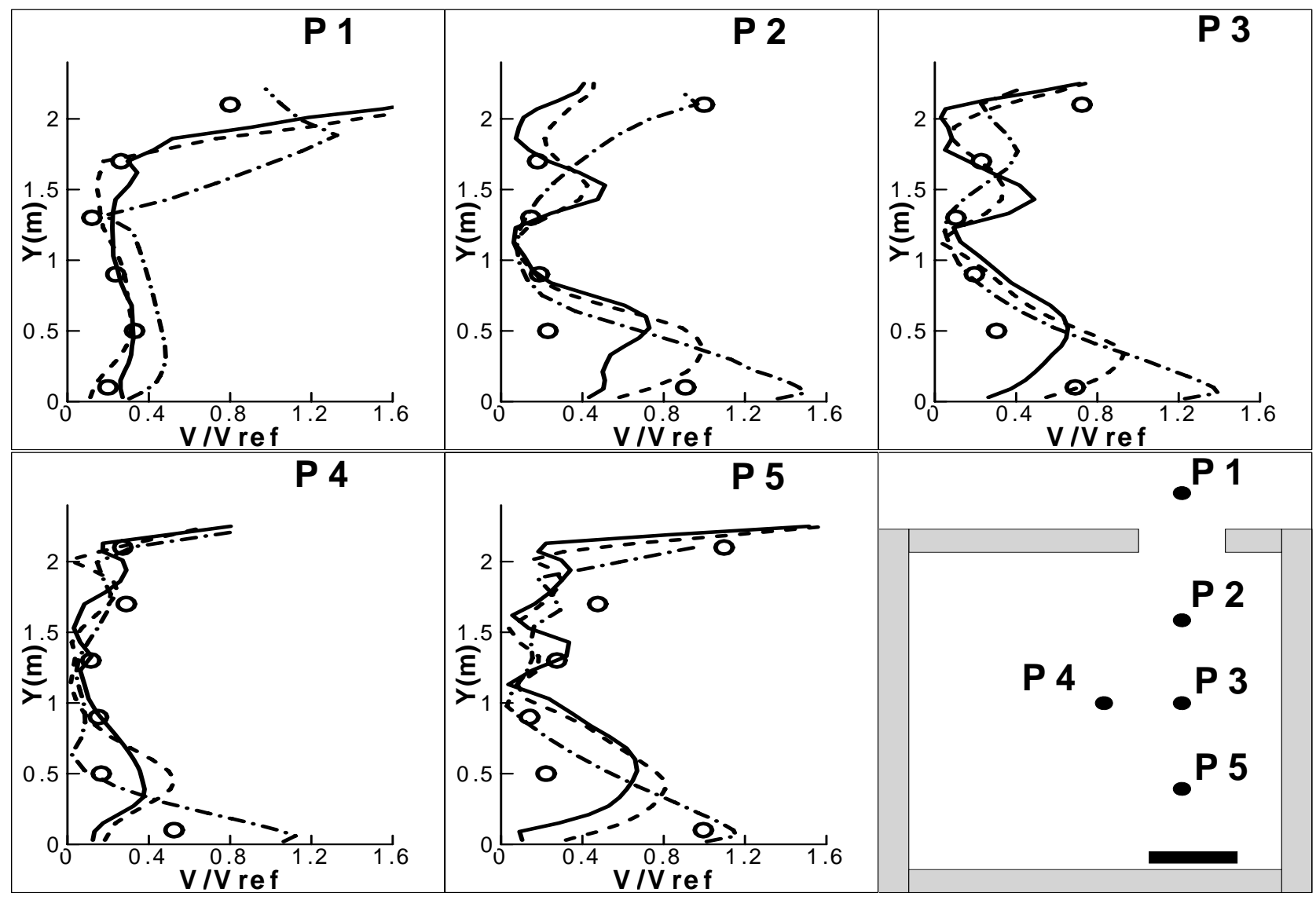

Figure 9. Comparison of the computed velocity profiles with the measured data at the five positions in and around the chamber with an open door. Circles: Experimental data; Solid lines: the SS model of LES; Dashed lines: the FDS model of LES; Dash-dot lines: the steady RANS modeling.

Figure 10 shows the measured turbulence energy spectra of the air velocity in the opening vicinity (at P1 and P2 positions shown in Figures 8 and 9) for the door case. Very similar to wind-driven ventilation, Figures 10(a) and 10(b) show that turbulence energy spectra of the air velocity remain the same entering the room from outside. Since the outdoor air (lab space) does not have a dominant flow, the outdoor air near the upper part of the opening is thus strongly influenced by the air coming from inside. Therefore, the energy spectra outside is the same as that inside as shown in Figures 10(c) and 10(d) This means that the airflow maintains its flow characteristics after going through the opening. In fact, the flow characteristic is the same between inside and outside air. The four figures shown in Figure 10 are nearly the same. The figures also show that the energy is mostly contained in the low-frequency region, less than $10^{-1} \mathrm{~Hz}$, which has the characteristics of natural winds ( $\mathrm{hu} 2000$ ). This frequency is one order magnitude lower than that for wind-driven natural ventilation. The lower frequency turbulence energy in the buoyancy-driven flow indicates that the energy is mainly contained in larger eddy motion. The high frequency, small eddies are not very important in buoyancy-driven ventilation. In contrast, the higher frequency turbulence energy in wind-driven ventilation means that fluctuating flow plays an important role in determining the ventilation rate through the building. 


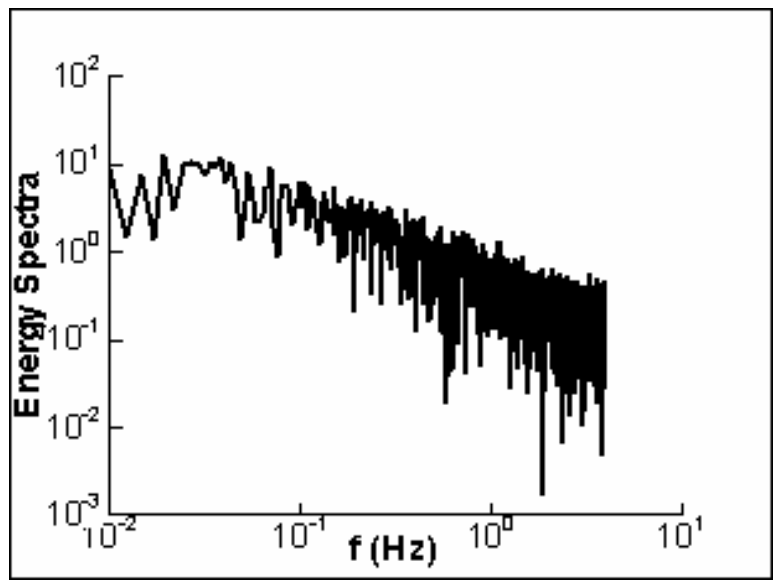

(a) $\mathrm{H}=0.5 \mathrm{~m}$ from the floor at $\mathrm{P} 1$.

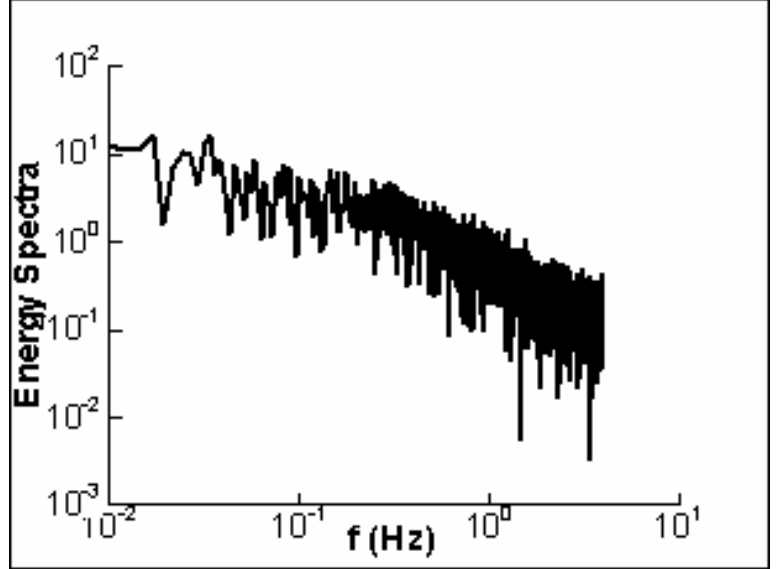

(c) $H=1.7 \mathrm{~m}$ from the floor at $\mathrm{P} 1$.

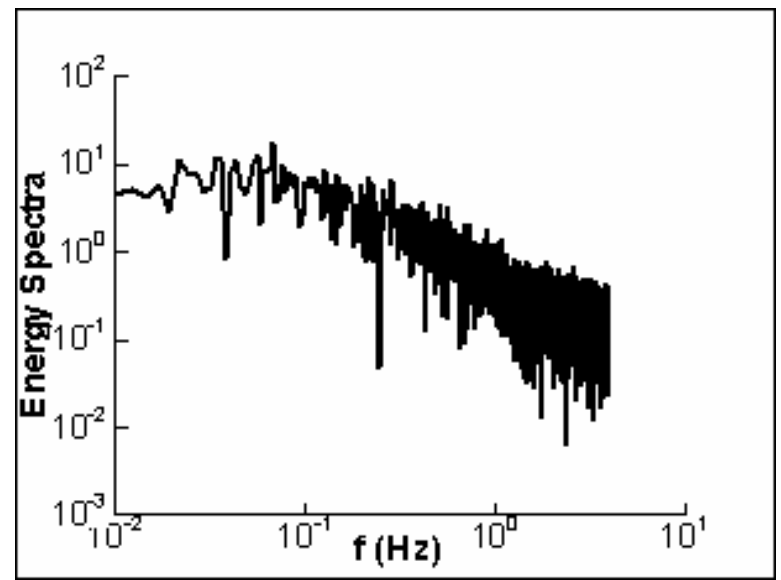

(b) $\mathrm{H}=0.5 \mathrm{~m}$ from the floor at $\mathrm{P} 2$.

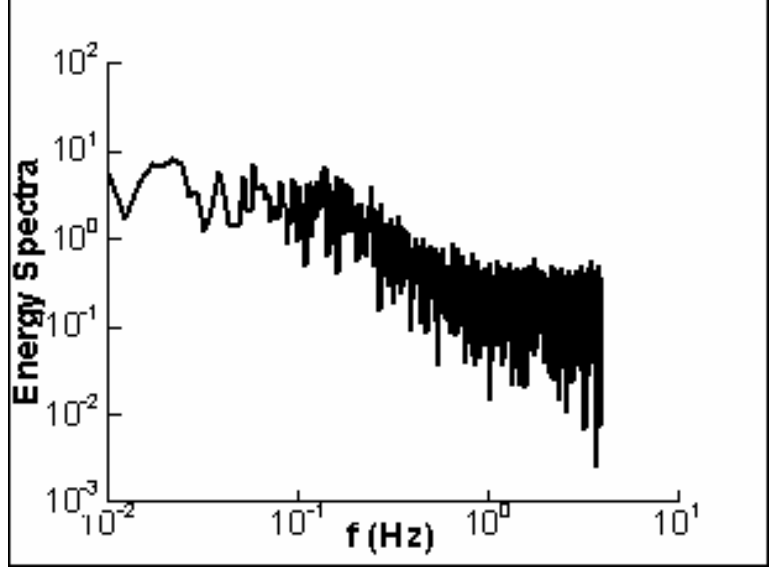

(d) $\mathrm{H}=1.7 \mathrm{~m}$ from the floor at $\mathrm{P} 2$.

Figure 10. The measured turbulence energy spectra in the opening vicinity for the open door case.

Figure 11 shows the computed turbulence energy spectra by LES. The shapes of the spectra distributions are very similar to those obtained from the measurements. The computed results also show that the energy is contained in low-frequency regions for both outside and inside air. The energy spectra distributions at the opening were also computed, which were not available from the measurements. The energy spectra at the lower part of the opening ( $\mathrm{H}=0.5 \mathrm{~m}$ from the floor) are similar to those inside and outside of the room. At the upper part of the opening, however, the peak energy is shifted to the high-frequency region (close to $1 \mathrm{~Hz}$ ). This is due to the fact that the sharp upper frame of the opening disturbs the flow field; thus, more energy is drawn from large eddies to small eddies. For the lower part of the opening, there is no obstacle blocking the airflow. The airflow can enter the room smoothly, and most energy is still contained in low-frequency region. 


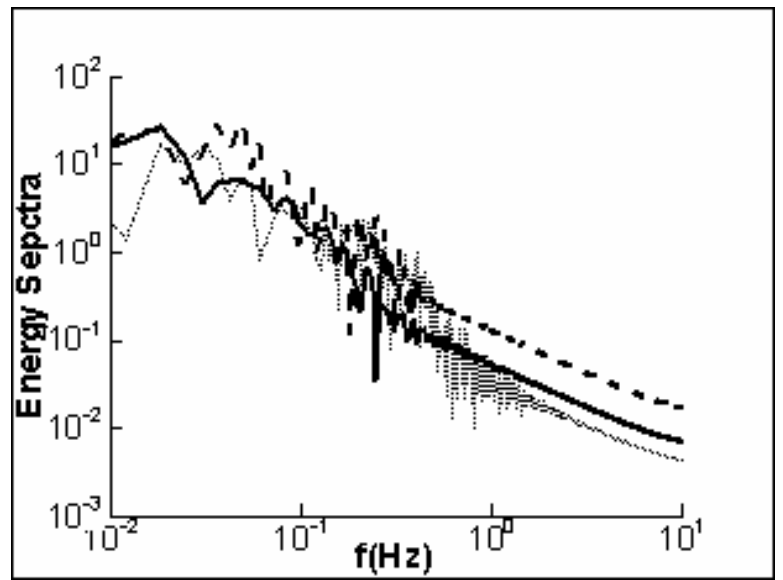

(a) $H=0.5 \mathrm{~m}$ from the floor

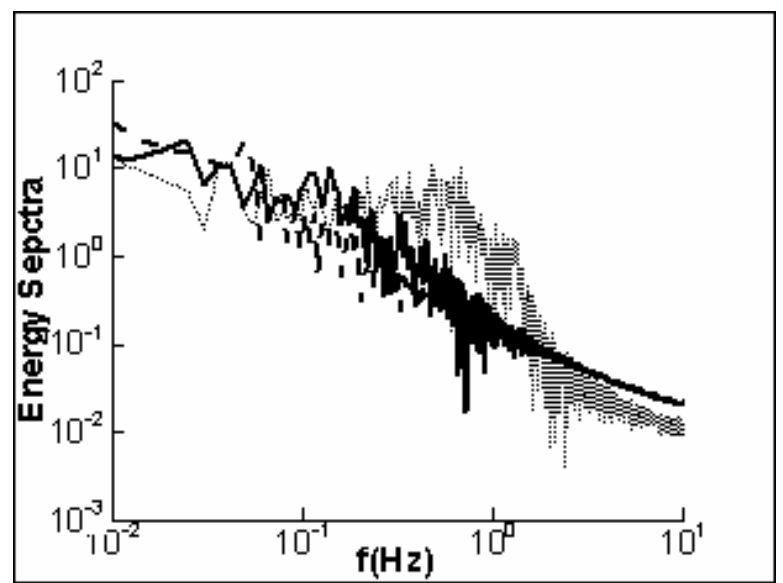

(b) $\mathrm{H}=1.7 \mathrm{~m}$ from the floor

Figure 11. The computed turbulence energy spectra in the opening vicinity for the open door case. Solid lines: P1 (outside of the room); Dashed lines: P2 (inside of the room); Dotted lines: at the opening.

The current experiment used a modified constant injection method to measure the ventilation rate. Based on the definition of ventilation rate, it can be computed by integrating the velocity at the opening. Jiang and Chen (2001) proposed two integration methods. The first one is to extract the mean velocity along the opening, and integrate the mean velocity to get the mean ventilation rate, $\mathrm{Q}_{\text {mean }}$. The other way is to extract the instantaneous velocity along the opening and determine the average instantaneous ventilation rate, $\mathrm{Q}_{\mathrm{ins}, \mathrm{T}}$, over a time period of $\mathrm{T}$. Since the calculation of $\mathrm{Q}_{\mathrm{ins}, \mathrm{T}}$ requires the transient flow field, the steady RANS modeling cannot provide this value.

Tables 2 shows the ventilation rates computed with the two methods. The LES results agree well with the experimental data. The steady RANS modeling gives much higher ventilation rates. Table 2 also shows no significant difference between the mean ventilation rate and the average instantaneous ventilation rate. This is different from single-sided, wind-driven ventilation, where the average instantaneous ventilation rate is much higher than the mean value, since the fluctuating flow field plays a more important role there (Jiang and Chen 2001). On the other hand, the mean pressure difference across the opening in the singlesided, buoyancy-driven natural ventilation case is about ten times larger than the fluctuating pressure (Jiang and Chen 2003). Therefore, the mean flow field plays a more important role in buoyancy-driven natural ventilation. That is why the mean ventilation rate and the average instantaneous ventilation rate are almost the same for the buoyancy-driven flow.

Table 2 Air exchange rate for the door case (ACH)

\begin{tabular}{|l|l|l|l|l|l|l|}
\hline & Experimental & \multicolumn{2}{l|}{ RANS $(\mathrm{k}-\varepsilon)$} & \multicolumn{2}{|l|}{ LES (FDS model) } & \multicolumn{2}{l|}{ LES (SS model) } \\
\cline { 4 - 7 } & measurement & $\mathrm{Q}_{\text {mean }} / \mathrm{V}$ & $\mathrm{Q}_{\text {ins }} / \mathrm{V}$ & $\mathrm{Q}_{\text {mean }} / \mathrm{V}$ & $\mathrm{Q}_{\text {ins }} / \mathrm{V}$ & $\mathrm{Q}_{\text {mean }} / \mathrm{V}$ \\
\hline $\mathrm{ACH}$ & $9.18-12.6$ & 15.2 & 10.6 & 10.5 & 10.4 & 10.2 \\
\hline
\end{tabular}

\section{Conclusions}

Three CFD models, steady RANS modeling, unsteady RANS modeling, and LES, were used to simulate wind-driven and buoyancy-driven natural ventilation. The air temperature, velocity, and ventilation rate predicted by the LES agree better with the measured data than those obtained by the steady and unsteady RANS modeling. The energy spectra computed by LES is also in qualitative agreement with the measured data. However, the LES model needs much longer computing time than the RANS modeling does. 
The results from this investigation have also confirmed that wind-driven ventilation contains energy in frequencies higher than buoyancy-driven ventilation. The fluctuating flow that contains more high frequency energy plays an important role in determining ventilation rate for wind-driven natural ventilation than for buoyancy-driven natural ventilation. If the wind can penetrate to indoors, such as cross ventilation, the frequencies of indoor flow energy are also higher due to direct energy transport. Otherwise, the energy of indoor airflow is contained in lower frequencies. For buoyancy-driven, singlesided ventilation, the turbulence energy is mostly in lower frequencies for both indoor and outdoor air. The fluctuating pressure across the openings is much smaller than the mean pressure difference. Unlike wind-driven ventilation, there is no significant difference between the mean ventilation rate and the average instantaneous ventilation rate in the buoyancy-driven ventilation.

\section{Acknowledgement}

This work is supported by the U.S. National Science Foundation under grant CMS-9877118.

\section{References}

Allard, F. "Natural ventilation in buildings: a design handbook", James \& James, London, UK. 1998.

Allocca, C. "Single-sided natural ventilation: design analysis and general guidelines," M.Sc. Thesis, 116 pages, Department of Mechanical Engineering, Massachusetts Institute of Technology, Cambridge, MA. 2001.

Etheridge, D., Sandberg, M. "Building ventilation: theory and measurement", John Wiley and Sons, Chichester; New York, 1996.

Hanzawa, H., Melikow, A.K., Fanger, P.O. "Airflow characteristics in the occupied zone of ventilated spaces”, ASHRAE Transactions. 1987 93 (1) pp524-539.

Jiang, Y., Chen, Q. "Study of natural ventilation in buildings by large eddy simulation", J. Wind Eng. Ind.

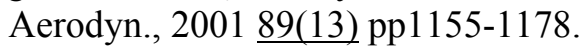

Jiang, Y, "Study of natural ventilation in buildings with large eddy simulation", Ph.D. Thesis, Building Technology Program, Massachusetts Institute of Technology, 2002.

Jiang, Y., Chen, Q., "Effect of fluctuating wind direction on cross natural ventilation in buildings from large eddy simulation", Building and Environment. 200237 pp379-386.

Jiang, Y., Alexander, D., Jenkins, H., Arthur, R. and Chen, Q. "Natural ventilation in buildings: Measurement in a wind tunnel and numerical simulation with large eddy simulation", Journal of Wind Engineering and Industrial Aerodynamics. 2003 91(3) pp331-353.

Jiang, Y. and Chen, Q. "Buoyancy-driven single-sided natural ventilation in buildings with large openings", International Journal of Heat and Mass Transfer. $2003 \underline{46}$ pp973-988.

Katayama T., Tsutsumi J., Ishii A., "Full-scale measurements and wind tunnel tests on cross-ventilation", J. Wind Eng. Ind. Aerodyn. 1992 41-44 pp 2553-2562.

Launder, B.E., Spalding, D.B., "The numerical computation of turbulent flows", Computer Methods in Applied Mechanics and Energy. $1974 \underline{3}$ pp269-289.

Ohba, M., Irie K., Kurabuchi, T. "Study on airflow characteristics inside and outside a cross-ventilation model, and ventilation flow rates using wind tunnel experiments", J. Wind Eng. Ind. Aerodyn. 2001 $\underline{89}$ pp1513-1524.

Rodi, W., Ferziger, J.H., Breuer, M., Pourquié, M. "Status of large eddy simulation: results of a workshop", Journal of Fluids Engineering. $1997 \underline{119}$ pp248-262.

Smagorinsky, J. "General circulation experiments with the primitive equations. I. The basic experiment", Monthly Weather Review. 1963 91 pp99-164.

Zhang, W., Chen, Q., "Large eddy simulation of indoor airflow with a filtered dynamic subgrid scale model", International J. of Heat and Mass Transfer. 200043 (17) pp3219-3231.

Zhu, Y. "Research on the fluctuant characteristics of natural wind and mechanical wind", M.Sc. Thesis, Department of Thermal Engineering, Tsinghua University, Beijing, P.R. China. (in Chinese), 2000. 